Revista "Política y Estrategia" No 129, 2017, pp. 157-187

ISSN 0716-7415 (versión impresa) ISSN 0719-8027 (versión en línea)

Academia Nacional de Estudios Políticos y Estratégicos

Cambio climático y producción de cultivos anuales esenciales. Una mirada desde la seguridad alimentaria en Chile

Carlos Méndez Notari, Roberto Araya-Valenzuela

\title{
CAMBIO CLIMÁTICO Y PRODUCCIÓN DE CULTIVOS ANUALES ESENCIALES. UNA MIRADA DESDE LA SEGURIDAD ALIMENTARIA EN CHILE ${ }^{\infty}$
}

\author{
CARLOS MÉNDEZ NOTARI* \\ ROBERTO ARAYA-VALENZUELA**
}

\begin{abstract}
RESUMEN
La investigación tiene como objetivo analizar si las políticas públicas que hoy definen las reglas del juego para el desarrollo productivo en la agricultura permiten mitigar los efectos relacionados con el calentamiento global, y si estas son suficientes para evitar que el cambio climático presione sobre las dificultades ya existentes en el sector agrícola, o para impedir el surgimiento de nuevos factores de riesgo o amenazas que afecten la seguridad alimentaria del país. Así mismo, busca proponer algunas recomendaciones para el diseño de políticas públicas que permitan minimizar los riesgos y amenazas en relación con la adaptación de la producción agrícola al cambio climático y, por ende, asegurar el acceso físico, social y económico a los alimentos suficientes y nutritivos que satisfagan las necesidades de la población nacional y atenúen su efecto el ámbito multidimensional de la seguridad. En tal sentido, se busca responder a la siguiente pregunta: ¿Qué desafíos plantea el cambio climático a la agricultura chilena en materia de seguridad alimentaria?

Palabras clave: Seguridad alimentaria - cambio climático - Índice de Seguridad Alimentaria - sector agrícola - cultivos anuales esenciales.
\end{abstract}

\footnotetext{
Licenciado en Educación por la Universidad de Los Lagos, Magíster y Doctor por la Universidad de Santiago de Chile y Postdoctor por la Universidad Nacional de Córdoba, Argentina. Actualmente se desempeña como Jefe del Departamento de Historia de la Escuela Militar del Libertador Bernardo O Higgins Riquelme y profesor en la Universidad del Desarrollo. Chile. camhistoria@hotmail.com

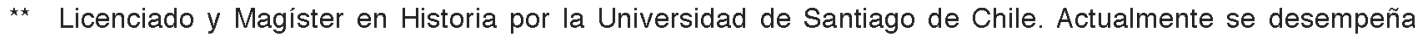
como Investigador asociado, CIHEAP-FAE, Universidad de Santiago de Chile. Chile. roberto.araya28@ gmail.com

- Fecha de recepción: 280417

Fecha de aceptación: 310517
} 


\title{
CLIMATE CHANGE AND ESSENTIAL ANNUAL CROP PRODUCTION. A VIEW FROM FOOD SECURITY IN CHILE
}

\begin{abstract}
This research has the objective of analyzing whether the public policies that today define the rules for productive development in agriculture can mitigate the effects related to global warming and if these are sufficient to prevent the pressing of climate change over the difficulties already existing in the agricultural sector or, to prevent the emergence of new risk factors or threats that affect the country's food security. It also seeks to propose some recommendations for the design of public policies to minimize the risks and threats related to the adaptation of agricultural production to climate change and, therefore, to ensure physical, social and economic access to sufficient food and nutritious foods that meet the needs of the national population and mitigate its effects on the multidimensional sphere of the security. In this sense, we try to answer the following question: What challenges does climate change pose to Chilean agriculture in terms of food security?
\end{abstract}

Key words: Food security - climate change - Global Food Security Index - agricultural sector - annual crops essential.

\section{INTRODUCCIÓN}

Al menos durante las últimas tres décadas el cambio climático se ha posicionado como un fenómeno mundial crecientemente analizado desde distintas aristas y disciplinas ${ }^{1}$. En el presente estudio este es analizado bajo la perspectiva de conocer sus posibles efectos sobre los rendimientos agrícolas en Chile y el mundo, y en tanto, sobre la previsible disponibilidad de alimentos ya sea en el mercado local como en el internacional. Concretamente buscamos indagar ¿en qué medida el cambio climático puede afectar la provisión de algunos cultivos anuales esenciales?

BARROS, Vicente. El Cambio Climático Global. ¿Cuántas catástrofes antes de actuar? Buenos Aires, Libros del Zorzal, 2005. 176p. STERN, Nicholas. El informe Stern: la verdad sobre el cambio climático. Barcelona, 2007, 389p. MUÑOZ, Francisco. La política del cambio climático. Madrid, Alianza, 2010. 303p. BATES, B. y otros. El cambio climático y el agua. Ginebra, PNUMA y Organización Meteorológica Mundial, 2008, 212p. ORDOÑES, José Antonio y MASERA, Omar. Captura de carbono ante el cambio climático. Madera y Bosques, s.I., 7(1): 3-12, 2001. ALDUNCE, Paulina, NERI, Carolina y SZLAFSZTEIN, Claudio. Hacia la evaluación de prácticas de adaptación ante la variabilidad y el cambio climático. s.I., NUMA / UFPA, 2008. 
En concomitancia se han trazado tres objetivos específicos: 1) Identificar las principales amenazas o los factores de riesgo para la seguridad alimentaria de Chile. 2) Profundizar en el conocimiento sobre los esfuerzos que se realizan actualmente, y los que se proyectan, para la adaptación de la agricultura chilena al cambio climático y mitigar sus efectos, con enfoque en el marco legal, institucional y financiamiento. 3) Conocer las buenas prácticas que se están llevando a cabo sobre integración del cambio climático en la planificación y el marco regulatorio que tutela el esquema productivo del sector agrícola en el Cono Sur, así como las principales sugerencias que organismos multilaterales como la FAO han efectuado sobre esta materia para el diseño de políticas públicas.

Sin desconocer el aporte de algunas investigaciones dedicadas tanto a la presentación y análisis de los resultados entregados por el Índice Global de Seguridad Alimentaria ${ }^{2}$, como a estudiar las características, ritmos y escenarios prospectivos que se desprenden del fenómeno del cambio climático en Chile ${ }^{3}$, dichas perspectivas no han puesto atención en analizar este asunto desde la perspectiva de la seguridad alimentaria de la nación y todos sus habitantes, así como los posibles efectos que tendría en el ámbito de la seguridad nacional bajo la perspectiva de los riesgos a la seguridad multidimensional, sentido en el cual es orientada la presente investigación. Para ello, serán de vital importancia algunos informes emitidos por paneles de expertos en materias de cambio climático y seguridad alimentaria ${ }^{4}$.

En cuanto a las fuentes, la información empleada se extrajo de documentos generados por organismos públicos y de literatura especializada. Estas fuentes se examinaron mediante la técnica de análisis de contenido.

Respecto al primer tipo de fuentes, destacan principalmente los resultados anuales publicados por el Global Food Security Index (GFSI) entre los años

2 MIA, Irene. Midiendo el estado de la seguridad alimentaria en Chile en una perspectiva internacional. Los hallazgos del Índice de Seguridad Alimentaria. Santiago, The Economist, Economist Intelligence Unit, 2013. 28p.

3 SHERIDAN, Jennifer y BICKFORD, David. Shrinking body size as an ecological response to climate change. Nature Climate Change, s.I., 1(8): 401-406, october, 2011. SCHMIDHUBER, Josef y TUBIELLO, Francesco. Global food security under climate change, Proceedings of the National Academy of Sciences, Boston, 104(50): 19703-19708, december, 2007. NEUESCHWANDER, Aquiles y ZABALETA, Juan. El Cambio Climático en el Sector Silvoagropecuario de Chile. Fundación para la Innovación Agraria, Santiago, 29 noviembre, 2010. CONDE, Cecilia y SALDAÑA, Sergio. Cambio climático en América Latina y el Caribe: impactos, vulnerabilidad y adaptación. Ambiente y Desarrollo, Santiago, 23(2): 23-30, 2007. OFICINA DE CAMBIO CLIMÁTICO. Plan Nacional de Adaptación al Cambio Climático. Santiago, Ministerio del Medio Ambiente, 2014, 55p. GARREAUD, René. Cambio climático: Bases físicas e impactos en Chile. Tierra Adentro, Santiago, (93): 13-19, marzo-abril, 2011. CLARO, Edmundo. Integrando la adaptación al cambio climático en las políticas de desarrollo: ¿Cómo estamos en Chile? REDESMA [online], 63(2): 63-72, 2008. SANTIBAÑEZ, Fernando. El cambio climático y los recursos hídricos en Chile. Santiago, ODEPA, 2016. 60p.

4 Organización de las Naciones Unidas para la Alimentación y la Agricultura. Cambio climático y seguridad alimentaria: un documento marco. Roma, FAO, 2007. 24p. HLPE. La seguridad alimentaria y el cambio climático. Un informe del Grupo de alto nivel de expertos en seguridad alimentaria y nutrición del Comité de Seguridad Alimentaria Mundial, Roma, HLPE, 2012. 115p. 
2012 y 2015, difundidos en el portal http://foodsecurityindex.eiu.com. El análisis pormenorizado de los tópicos sobre los que se constituye este indicador permitirá identificar -bajo el prisma de criterios internacionales- las principales amenazas o los factores de riesgo para la seguridad alimentaria en Chile. Ello no excluye la posibilidad de incorporar tópicos ausentes que parezcan pertinentes desde el punto de vista de la Seguridad y Defensa.

En relación al marco regulatorio y prácticas institucionales que se realizan actualmente, y las que se proyectan, para la adaptación de la agricultura chilena al cambio climático y mitigar sus efectos, revisaremos principalmente las actas de la Comisión Asesora del Ministro de Agricultura para la Industria Alimentaria Chilena ${ }^{5}$.

Finalmente, para conocer sobre los esfuerzos que los países de la región se encuentran realizando en el área de cambio climático, con enfoque en el marco legal, institucional y financiamiento, nos valdremos de los perfiles por países existentes en el Portal Regional por la Transferencia de Tecnología y la Acción frente al Cambio Climático en América Latina y el Caribe ${ }^{\varsigma}$, los cuales contienen información sobre la integración del cambio climático en la planificación y el marco regulatorio de los países de América Latina y algunas de las numerosas buenas prácticas que se están llevando a cabo en la región. Así también, pondremos particular atención en un conjunto de informes generados por la $F A O$, que nos permitan identificar algunas recomendaciones que pudieran constituirse en aportes concretos para los organismos vinculados al sector agrícola y así establecer eventuales opiniones a las políticas públicas o políticas de Estado, susceptibles de mejorar.

\section{LA SEGURIDAD ALIMENTARIA MIRADA DESDE EL GLOBAL FOOD SECURITY INDEX}

En 2012, la Economist Intelligence Unit (EIU) ${ }^{7}$ fue encargada por la compañía científica DuPont para la realización de un estudio cuyo principal objetivo

\footnotetext{
Por ser posterior a la fecha de elaboración de este artículo, hemos omitido el análisis de los alcances y posible repercusión de la creación de la Agencia Nacional para la Sustentabilidad y el Cambio Climático/ Comité CORFO, anunciada por la Presidenta de la República, Michelle Bachelet, en el discurso del 21 de mayo de 2016. En dicha ocasión la Presidenta adelantó que el objetivo principal de la agencia sería "internalizar en Chile los compromisos internacionales de nuestro país frente al cambio climático y los planes de acción nacionales en esta materia, mediante alianzas público-privadas; que permita, además, dar cumplimiento a las recomendaciones de la OCDE respecto a la necesidad de contar con una institución climática en Chile". Así mismo, hemos omitido el análisis de los contenidos del ante proyecto Plan de Acción Nacional de Cambio Climático 2017-2022, publicado recientemente por el Ministerio del Medio Ambiente.

6 http://www.cambioclimatico-regatta.org/index.php/es/perfiles-de-paises

7 La Unidad de Inteligencia de The Economist es parte del grupo The Economist, la principal fuente de análisis sobre los negocios internacionales y asuntos mundiales. Fundada en 1946 como una unidad interna de investigación para el periódico The Economist, ofrece inteligencia empresarial, previsiones y asesoramiento
} 
era producir un índice que permitiera evaluar el estado de la seguridad alimentaria en diversos países, así como identificar las causas de la inseguridad alimenticia en cada uno de ellos. Su resultado fue la creación del Global Food Security Index (GFSI). Este índice clasifica 109 países en función de sus niveles relativos de seguridad alimentaria, utilizando 28 indicadores de seguridad alimentaria que monitorean el impacto permanente de las inversiones agrícolas, colaboraciones y políticas públicas de todo el mundo, agrupados en tres categorías: asequibilidad, disponibilidad, calidad y seguridad ${ }^{8}$.

Dependiendo de la evaluación a cada uno de estos 28 indicadores, los países van acumulando puntaje que finalmente determina su puntuación global. Sobre la base de este puntaje, los 109 países son ubicados dentro de un ranking y estratificados según su rendimiento de la siguiente manera: el mejor rendimiento (entre 100 y 76 puntos); buen rendimiento (entre 75 y 51 puntos); moderado rendimiento (entre 50 y 26 puntos); necesita mejorar (entre 25 y 0 puntos).

Según su última actualización, efectuada el 2015 (Cuadro $N^{\circ} 1$ ), tal cual ocurrió el año anterior, Chile lidera América Latina con una puntuación global de 74.3. En la desagregación por categorías, destaca entre sus pares sudamericanos con una evidente ventaja en materia de disponibilidad y asequibilidad de alimentos, secundándole, en el caso de la primera categoría, Uruguay a 3.8 puntos de distancia, y Brasil, en el caso de la segunda, a 5.4. Mientras tanto, en calidad y seguridad alimentaria, Chile figura tercero tras Argentina y Brasil.

Esta posición de liderazgo chileno en el GFSI dista de ser un hecho aislado, pues, como se puede observar en el Gráfico $N^{\circ} 1$, desde su creación en el 2012 Chile ha obtenido la puntuación más alta entre sus pares sudamericanos. Otro aspecto que se desprende de los datos es el incremento sostenido de su puntuación año tras año, situación que tan solo se replica en el caso de Ecuador, pues el grueso de los demás países de la región se ha estancado, o bien han tenido comportamientos fluctuantes. Expuesto en cifras, el 2015 la puntuación de Chile mejoró a 74.3 en comparación a un 72.5 en 2014, 70.3 en 2013 y a un 68,9 en 2012, quedando como el país mejor clasificado entre los países de ingresos medio-altos en el mundo, a la vez que está muy próximo de recibir la clasificación de "mejor rendimiento".

a más de 1,5 millones de tomadores de decisiones de las empresas más importantes del mundo, las instituciones financieras, los gobiernos y las universidades.

8 MIA. Loc. Cit. 


\section{CUADRO $\mathrm{N}^{\circ} 1$ \\ Puntuación obtenida por los países sudamericanos en el GFSI de 2015}

\begin{tabular}{|cccccc|}
\hline Ranking & País & $\begin{array}{c}\text { Puntuación } \\
\text { Global }\end{array}$ & $\begin{array}{c}\text { Asequibilidad } \\
\text { Disponibilidad }\end{array}$ & $\begin{array}{c}\text { Calidad y } \\
\text { Seguridad }\end{array}$ \\
\hline 27 & Chile & 74.3 & 77.1 & 73.3 & 70.2 \\
\hline 33 & Uruguay & 69.4 & 69.3 & 69.5 & 69.2 \\
\hline 36 & Brasil & 67.4 & 71.7 & 61.1 & 73.7 \\
\hline 48 & Argentina & 67.1 & 69.5 & 62.4 & 74.1 \\
\hline 53 & Venezuela & 61.7 & 68.7 & 53.4 & 67.4 \\
\hline 64 & Colombia & 59.6 & 59.9 & 59.5 & 59.1 \\
\hline 61 & Perú & 58.6 & 61.0 & 56.2 & 59.6 \\
\hline 67 & Ecuador & 56.0 & 55.6 & 54.9 & 59.7 \\
\hline
\end{tabular}

FUENTE: Elaboración propia en base a los datos de http://foodsecurityindex.eiu.com/lndex

En el índice publicado el 2015 también se reconoció a Chile la fortaleza ${ }^{9}$ en once indicadores, ellos fueron:

- 100 Presencia de los programas de redes de seguridad alimentaria.

- 100 Los niveles de nutrición.

- $98 \quad$ Proporción de la población bajo la línea de la pobreza mundial.

- 94.7 Seguridad alimentaria.

- $\quad 92.7$ Los aranceles de importación agrícola.

- $\quad 92.6 \quad$ La volatilidad de la producción agrícola.

- 89.9 Pérdida de alimentos.

- $\quad 87.3$ El consumo de alimentos como proporción del gasto de los hogares.

- $\quad 77.8$ Riesgo de la estabilidad política.

- 75 Corrupción.

- 75 El acceso a la financiación para los agricultores.

Ahora bien, estos alentadores resultados en ninguna medida significan la total ausencia de factores que pudiesen generar amenazas a la seguridad alimentaria. Para lograr la seguridad alimentaria, los cuatro componentes en su totalidad deben ser adecuados. Ellos son: disponibilidad, estabilidad, accesibilidad y utilización ${ }^{10}$.

9 En el GFSI las "fortalezas" se definen como cualquier puntuación por encima de 75,0.

10 FAO. Loc. Cit. 
A la luz de los datos obtenidos de la revisión de una serie de documentos publicados por ODEPA ${ }^{11}$, es necesario detenerse al menos en uno de los 28 indicadores evaluados por el GFSI (Gráfico $N^{\circ} 1$ ), este es la suficiencia del suministro $^{12}$, en su arista denominada suministro normal de comida.

Gráfico $N^{\circ} 1$

Tendencias año tras año para el GFSI en los países sudamericanos ${ }^{13}$ y Estados Unidos (2012-2015)

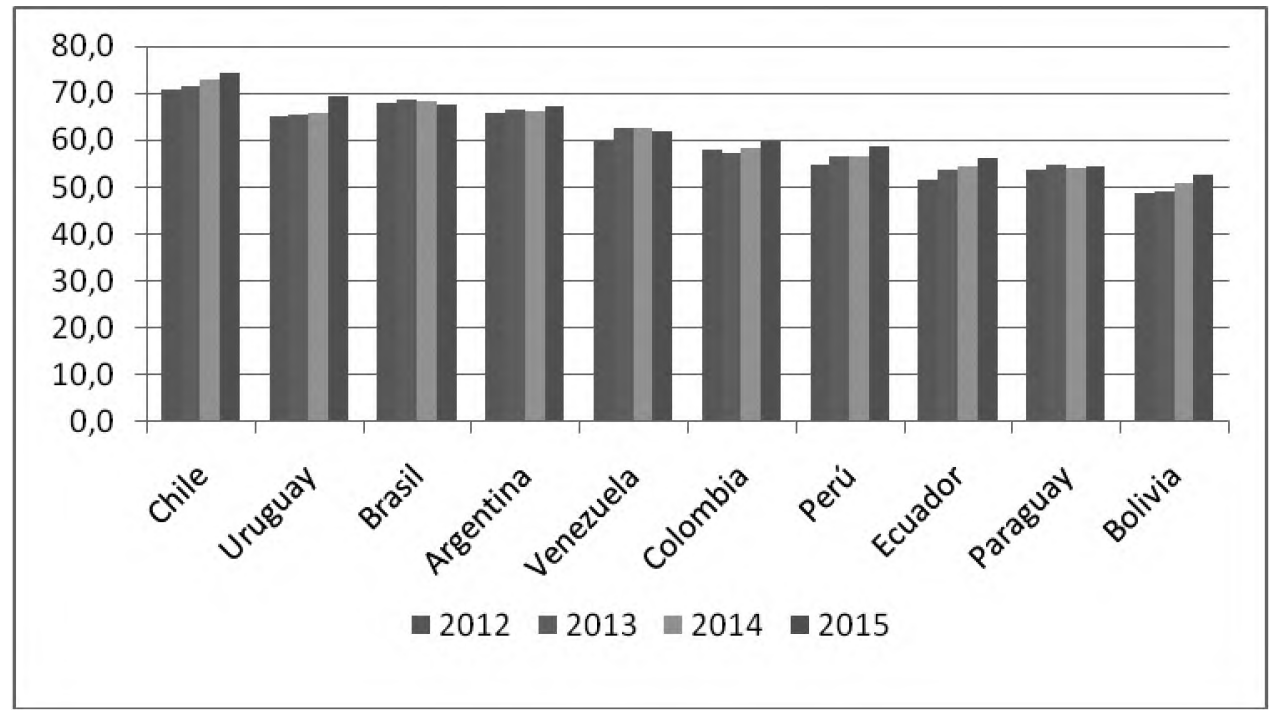

FUENTE: Elaboración propia en base a los datos de http:/ffoodsecurityindex.eiu.com/Index

Gracias a ellos se constató que una parte importante del consumo aparente de trigo, maíz, arroz, poroto, lenteja y garbanzo a nivel nacional es cubierto por productos importados. Concretamente, se pudo establecer que en aquellos cultivos con menor incidencia de las importaciones (papas y cereales) el abastecimiento externo cubre entre un $40 \%$ y un $50 \%$ de los requerimientos de la

11 BANFI Piazza, Silvio. Evolución del mercado de las lentejas. Santiago, ODEPA, 2014. BANFI Piazza, Silvio. Cultivo de porotos en perspectiva. Santiago, ODEPA, 2014. BUZZETTI, Carolina y GARCÍA, Andrea. Trigo: situación y perspectivas. Santiago, ODEPA, 2015. Departamento de Política Agraria. Evolución del consumo aparente de los principales alimentos en Chile: 2003-2013. Santiago, ODEPA, 2014. MUÑOZ Villagrán, Marcelo. Maíz: alza en precios nacionales. Santiago, ODEPA, 2014. MUÑOZ Villagrán, Marcelo. Arroz: baja la producción mundial. Santiago, ODEPA, 2014. MUÑOZ Villagrán, Marcelo. Maíz: se aproxima una temporada complicada. Santiago, ODEPA, 2013. Oficina de Estudios y Políticas Agrarias. Consumo aparente de principales alimentos en Chile. Santiago, ODEPA, 2012. TAPIA Cruz, Bernabé. Mercado de la papa. Santiago, ODEPA, 2014.

12 Este es un indicador compuesto que mide la disponibilidad de alimentos a través del suministro de alimentos en kcal / cápita / día y los niveles de ayuda alimentaria.

13 No se consideró las dependencias, así como tampoco los siguientes países: Trinidad y Tobago, Guyana y Surinam. 
demanda doméstica, mientras en otros (particularmente leguminosas), la dependencia del mercado interno a los productos importados supera el 90\%. Esto quiere decir que, más del $50 \%$ de los requerimientos de cultivos anuales esenciales actualmente no son cubiertos por la producción nacional.

La liberalización de los suelos y el apabullante predominio de la lógica de la búsqueda de la máxima rentabilidad entre los productores agrícolas, parecen ser dos factores definitorios de esta creciente dependencia alimenticia. Sobre el segundo de ellos, los documentos publicados por ODEPA ya puntualizados son bastante reiterativos en señalar la estrecha relación existente entre el comportamiento de los precios internacionales, precios nacionales y nivel de producción nacional. Los precios de los mercados internacionales presionan al alza o a la baja el precio de la producción nacional, presión que actúa como incentivo o desincentivo sobre los productores agrícolas criollos. En consecuencia, la recuperación de las siembras de un cultivo en una determinada temporada depende del comportamiento de la variable precio a lo largo de la temporada anterior, en consecuencia es esencial incorporar fórmulas que integren nuevas normativas regulatorias y cambios estratégicos que permitan mejorar los procedimientos en el cultivo, gestión y comercialización.

Ahora bien, ¿de qué manera se entrelazan el crecimiento de la dependencia alimentaria del exterior en la provisión de algunos cultivos anuales esenciales y su suficiente disponibilidad para el consumo de los chilenos? Cuando existe un bajo coeficiente de auto aprovisionamiento, es decir, cuando el volumen y la composición de la producción han dejado de ser esenciales para la disponibilidad de determinados alimentos básicos, la suficiencia de su suministro está en gran medida sujeta a factores que no necesariamente son de control de la nación, como por ejemplo, las existencias en el mercado internacional de alimentos.

Entre los factores internos, uno que incide directamente sobre la capacidad de comprar estos alimentos en el mercado internacional es la existencia de divisas. Lo cual, a su vez, se relaciona directamente con la tasa de cobertura de las importaciones por las exportaciones agroalimenticias. Esto es de suma relevancia, pues cuando las divisas generadas por las exportaciones agroalimenticias no reportan las divisas que demanda la importación de los alimentos que no se producen en el país, el déficit ha de ser cubierto por divisas generadas a partir de la exportación de otro tipo de bienes. Cuando ello ocurre, se está frente a un sistema alimentario ${ }^{14}$ deficiente.

14 Un sistema alimentario es un conjunto de interacciones dinámicas entre los medios biogeofísicos y humanos y dentro de ellos, que influencian tanto las actividades como los resultados a lo largo de la cadena alimentaria (producción, almacenamiento, elaboración, distribución, intercambio, preparación y consumo). El resultado de su funcionamiento define el mayor o menor grado de seguridad alimentaria. FAO. Op. Cit. p. 4. 
Basar la disponibilidad alimentaria en una producción que no es nacional, pareciera ser una constante entre países pequeños que se desempeñan como grandes exportadores de productos minerales, industriales o agrícolas ${ }^{15}$. Tendencia que aflora justamente como una de las implicancias del proceso de transformación estructural del agro impulsado en Chile desde al menos mediados de la década de los noventa, en cuyo marco las tasas de crecimiento de los grupos de cultivos que conforman los llamados cultivos anuales esenciales (cereales, leguminosas y tubérculos), han experimentado un evidente detrimento en comparación con la producción forestal, frutícola y vitivinícola.

El riesgo de lo anterior -que al parecer para los creadores del índice no representa una amenaza, pues no lo consideran- radica por ejemplo en que el llamado "tirón de la demanda" de los países emergentes y su creciente demanda por alimentos, o el influjo de eventuales conflictos internos y catástrofes naturales en países productores, pudiesen en cualquier momento alterar tanto los requerimientos como los niveles de la producción mundial de determinados cultivos, y, en tanto, reducir las reservas mundiales que permiten a muchos países, entre ellos Chile, asegurar parte de la disponibilidad alimentaria.

Por otro lado, a estas alturas ya parece existir un consenso internacional en torno a las tendencias generales del cambio climático y su condición de factor alterador de la producción agrícola mundial. Como la existencia de grandes volúmenes de productos agrícolas depende en gran medida de la producción -inciden también otros factores como las condiciones de transporte, bodegaje y conservación de esta producción-, y, a su vez, incide directamente sobre la disponibilidad alimentaria, analizar las implicancias que el cambio climático puede tener, al menos, sobre la producción y disponibilidad de alimentos resulta ser de suma relevancia para proyectar escenarios en materia de seguridad alimentaria. Al respecto, estudios recientes señalan que existe un sólido y coherente patrón mundial discernible en torno a los impactos del cambio climático sobre la productividad de los cultivos, que podría tener consecuencias para la disponibilidad de alimentos. Es más, dichos estudios sostienen que la estabilidad de los sistemas alimentarios puede estar en riesgo en relación con el cambio climático debido a la variabilidad a corto plazo en la oferta ${ }^{16}$. Por ello, y en virtud de otros factores antes expuestos, se refuerza la idea del eventual riesgo que implica el significativo incremento de la dependencia alimenticia nacional para el abastecimiento de determinados cultivos anuales esenciales.

15 CHONCHOL, Jacques. Desafío alimentario: el hambre en el mundo. Santiago, LOM, 1991. 195p.

${ }_{16}$ WHEELER, Tim y VON BRAUN, Joachim. Climate change impacts on global food security. Science, s.I., 2013, 341(6145): 508-513, august, 2013. 


\section{CAMBIO CLIMÁTICO Y SEGURIDAD ALIMENTARIA}

Desde hace al menos una década viene desarrollándose un profuso e intenso debate científico en torno a los efectos del cambio climático a nivel mundial. Aun cuando no existen posiciones unánimes, los diversos enfoques prevén que se produzcan temperaturas extremas, escasez de agua e inundaciones, debido principalmente al aumento de las emisiones de gases de efecto invernadero (GEI) inducidos por la acción humana. Así mismo, advierten que algunos animales y plantas pueden reducirse en tamaño debido a las altas temperaturas y a las menores precipitaciones ${ }^{17}$, lo que limitará la disponibilidad de fuentes alimentarias esenciales para la nutrición del ser humano.

En otros términos, a consecuencia del calentamiento global, existe una alta probabilidad de que la agricultura a nivel mundial se vea seriamente afectada por una disminución en los rendimientos de los cultivos debido, principalmente, a las crecientes temperaturas y a las menores precipitaciones, lo que a su vez agudizará la inseguridad alimentaria. Otras de las consecuencias esperables son la disminución de la calidad de los cultivos, una mayor lixiviación de nitrógeno y erosión del suelo, y la menor disponibilidad de tierras y recursos hídricos para la actividad agropecuaria ${ }^{18}$.

Si bien los enfoques actualmente en uso proyectan que el impacto del cambio climático variará en función del sistema de producción agropecuaria y de su ubicación geográfica, son enfáticos en señalar que los gobiernos y los productores rurales a nivel mundial -especialmente el pequeño productor- deberán adaptar sus agroecosistemas a patrones climáticos variables e inestables, debido a que el cambio climático afectará el acceso a los alimentos, como así también su disponibilidad, estabilidad y uso ${ }^{19}$. En consecuencia, así como el resto de las regiones del planeta, América Latina y el Caribe deberán adaptar los cultivos y el ganado de sus diversos agroecosistemas al calentamiento global y a la escasez de agua. Por lo tanto, como ya lo advirtió el Banco Interamericano de Desarrollo (BID), los productores rurales deberán incorporar innovaciones tecnológicas y métodos de producción (incluido el cambio de cultivos) que sean económicamente rentables y respetuosos del medio ambiente. En concordancia con dichas proyecciones, el mismo BID ha planteado que los principales desafíos para la agricultura en este siglo serán mejorar el acceso a los alimentos, incrementar su oferta, aumentar su distribución, y acrecentar la capacidad de recuperación del sistema alimentario, al tiempo que se reducen las emisiones de GEI y se elimina la contaminación del aire y del agua producida por la actividad agropecuaria y el

\footnotetext{
SHERIDAN y BICKFORD. Loc. Cit.

ORTIZ, Rodomiro. El cambio climático y la producción agrícola. s.I., BID, 2012. 41p.

SCHMIDHUBER y TUBIELLO. Loc. Cit.
} 
uso de las tierras, evitando perjudicar el hábitat y la biodiversidad y eliminando en forma gradual las extracciones de agua no sostenibles ${ }^{20}$.

Puntualizando, entre los efectos del cambio climático que son importantes para la seguridad alimentaria, destacan:

1) Efectos en la fertilización del $\mathrm{CO}_{2}$ :

a) Aumento en la disponibilidad de dióxido de carbono para el crecimiento de las plantas.

2) Aumento de las temperaturas medias mundiales:

b) Aumento de las temperaturas máximas en días calurosos.

c) Aumento de las temperaturas mínimas en días fríos.

d) Aumento en la frecuencia anual de días calurosos.

e) Aumento en la frecuencia, duración e intensidad de las ondas de calor.

3) Cambios graduales en las precipitaciones:

f) Aumento en la frecuencia, duración e intensidad de las temporadas secas y las sequías.

g) Cambios en la periodicidad, localización y cantidades de lluvias y nevadas.

4) Aumento en la frecuencia e intensidad de fenómenos climáticos extremos:

h) Aumento en la frecuencia anual de vientos fuertes, lluvias copiosas, tormentas e inundaciones a menudo asociadas con tormentas tropicales y tornados.

5) Mayor variabilidad climática:

i) Mayor inestabilidad en las configuraciones climáticas estacionales.

j) Cambios en el inicio y final del transcurso de las estaciones.

6) Aumento del nivel del mar:

k) Inundación de hábitats humanos.

l) Infiltración de aguas salinas ${ }^{21}$.

Según los especialistas sobre cambio climático de la FAO, los cambios en las condiciones climáticas arriba señalados afectarán la seguridad alimentaria, impactando sobre todo los componentes de los sistemas alimentarios mundial, nacional y local. Independientemente de que los efectos de los cambios graduales en la temperatura y precipitación medias sean discontinuos, ya sean positivos o negativos, es probable que generen: cambios en la adaptabilidad de la tierra para diferentes tipos de cultivos y pasturas; alteraciones en la salud y productivi- 
dad de los bosques; modificación en la distribución, productividad y composición comunitaria de los recursos marinos; variaciones en la incidencia y vectores de diferentes tipos de plagas y enfermedades; pérdida de la biodiversidad y del funcionamiento del ecosistema en los hábitats naturales; cambios en la distribución de agua de buena calidad para los cultivos, el ganado y la producción pesquera continental; pérdida de tierras arables debido a la creciente aridez y a la salinidad asociada, disminución del agua subterránea y aumento del nivel del mar; transformaciones en las oportunidades para los medios de subsistencia; fluctuaciones en los riesgos de la salud; migración interna e internacional ${ }^{22}$.

Si bien el aumento de las temperaturas no es siempre negativo, estimaciones recientes sostienen que el incremento de las temperaturas máximas puede conducir a una reducción grave del rendimiento y a un fracaso reproductor en muchos cultivos anuales esenciales. Por ejemplo, el aumento de las temperaturas durante la noche reduce el rendimiento del arroz hasta un 10 por ciento por cada grado centígrado que aumente la temperatura mínima en la estación seca. En el caso del maíz, el rendimiento puede reducirse un 1,7 por ciento por cada gradodía por encima de $30^{\circ} \mathrm{C}$ en condiciones de sequía. Las temperaturas más altas también están asociadas con concentraciones más elevadas de ozono. El ozono es perjudicial para todas las plantas, pero la soja, el trigo, la avena, las judías verdes, los pimientos y algunos tipos de algodón son especialmente vulnerables ${ }^{23}$.

Resumiendo, el riesgo que implica el cambio climático radica en que está generando un aumento de la inseguridad acerca de la temperatura futura y de los regímenes de precipitación, lo cual hace intrínsecamente más riesgosas las inversiones en la agricultura y en otros medios de subsistencia que dependen del clima. Otro aspecto importante a considerar que determina la forma en que el cambio climático afecta a la seguridad alimentaria son las diferencias en el modo de producción agrícola, tanto a nivel local en una determinada región como en todo el planeta ${ }^{24}$. La transformación de los modelos de producción agrícola derivada de sus efectos, tendrá repercusiones en los rendimientos, afectando el suministro de alimentos a nivel local y mundial ${ }^{25}$, y en tanto, su disponibilidad.

Sobre esto último, una investigación conducida hace pocos años por David Lobell, referida al pasado reciente (1980-2008), comprueba que el aumento observado de las temperaturas en la segunda mitad del siglo $X X$ y comienzos del XXI, y los cambios consiguientes en las precipitaciones, han tenido diversos efectos demostrables en la agricultura en todo el mundo. Según se aprecia en la Figura $\mathrm{N}^{\circ} 1$, ello se traduce en cambios muy diferentes en los rendimientos

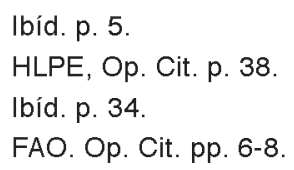


medios de algunos cultivos anuales esenciales de los principales productores a nivel mundial ${ }^{26}$.

Figura $N^{\circ} 1$

Efectos netos estimados de las tendencias climáticas de 1980-2008 sobre los rendimientos medios de los cultivos de los principales productores y la producción mundial

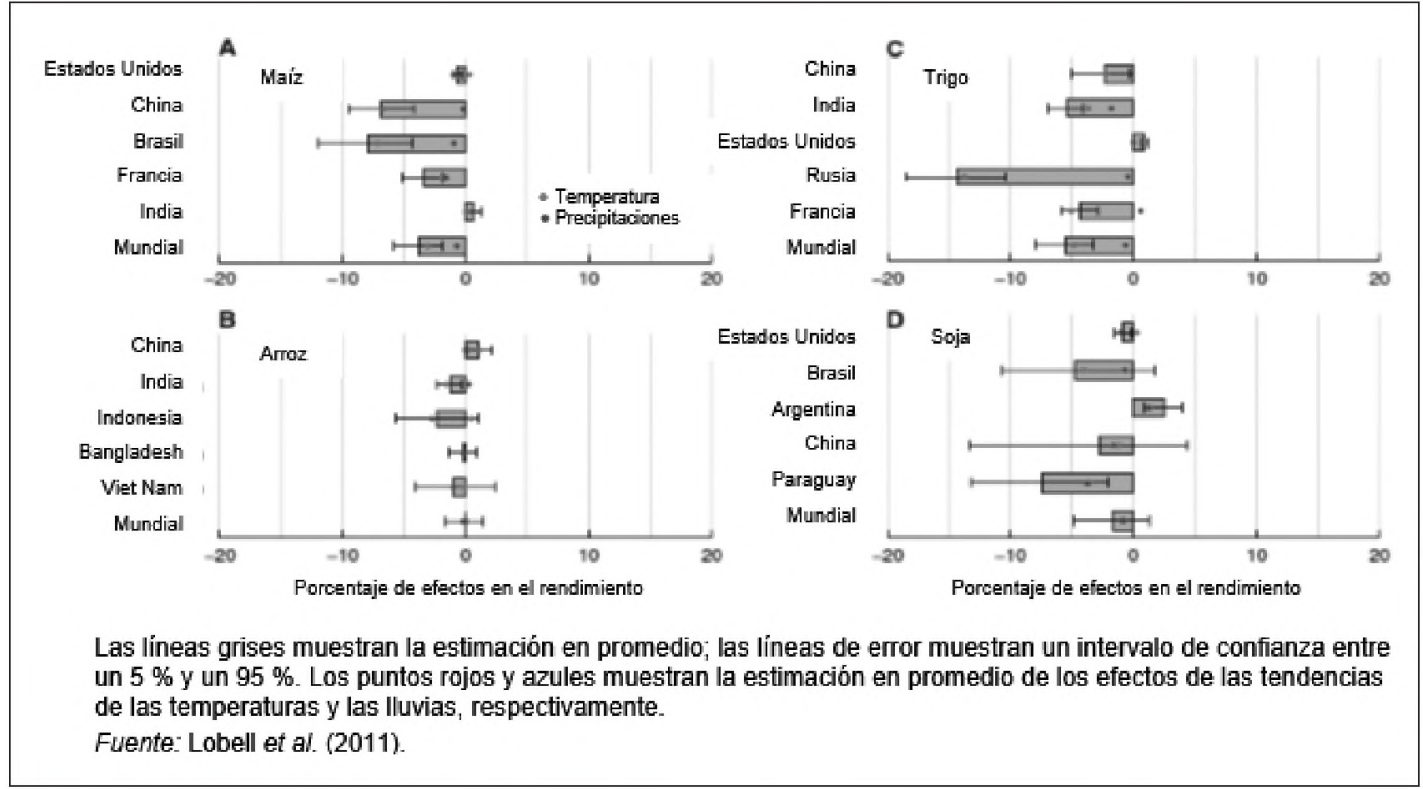

Se reconoce en el nivel de vulnerabilidad de cada país uno de los factores clave en la heterogeneidad de los efectos del cambio climático. La vulnerabilidad depende del grado de exposición de los sistemas, comunidades, familias e individuos al cambio climático. En general, se define con arreglo a tres dimensiones: la exposición a riesgos, su magnitud y la sensibilidad a los mismos. Que a su vez determinan la envergadura de sus efectos y la capacidad de respuesta y adaptación o resistencia ${ }^{27}$.

En cuanto a las proyecciones del cambio climático en chile, específicamente en su arista producción agrícola, se prevé que el rendimiento del trigo de secano disminuirá entre un 5 y un 10 por ciento en la zona septentrional y central de Chile debido a las sequías que se esperan en estas zonas; en las inmediaciones de la región del Biobío e incluso más al sur, el rendimiento de este cereal podría aumentar más de un 30 por ciento debido al incremento de temperaturas

26 LOBELL, David, SCHLENKER, Wolfram y COSTA-ROBERTS, Justin. Climate trends and global crop production since 1980. Science, s.I., 333(6042): 616-620, july, 2011.

27 HLPE. Op. Cit. p. 31. 
en el invierno ${ }^{28}$. Por su parte, los rendimientos del poroto, del maíz, la papa y la remolacha azucarera disminuirán desde el norte hasta la región del Biobío, aunque aumentarían en la costa, en la pre cordillera, y desde la Araucanía hacia el sur. Por otro lado, se proyecta que la productividad anual de las pasturas disminuirá en Atacama y desde Coquimbo hasta Los Lagos, debido a la menor disponibilidad de agua en los suelos de esas zonas, en tanto que aumentará en la región central de Chile y en el Altiplano.

También los rendimientos de las pasturas se reducirán en la cordillera oriental por efecto de la radiación solar, y lo mismo sucederá desde el Biobío hasta Los Lagos como consecuencia de periodos secos prolongados. Sin embargo, estos rendimientos se incrementarán hasta un 10 por ciento desde Valparaíso hasta el río Maule debido a las mayores temperaturas invernales. Por su parte, los rendimientos de la uva se reducirán en el norte de Chile debido al desarrollo prematuro del cultivo por efecto de las altas temperaturas esperadas para el invierno y la primavera. Estos menores rendimientos se registrarán también en la zona Metropolitana hacia el sur, debido a la menor radiación solar, a las altas temperaturas y precipitaciones, y a las heladas de final de primavera. Como contrapartida, la productividad del cultivo podría aumentar en las regiones del Maule y del Biobío, y lo mismo sucedería desde la Araucanía hacia el sur. En tanto, la productividad del durazno podría verse afectada al igual que la de la uva. Por último, los rendimientos de la manzana disminuirán en todo el país hasta la Araucanía, debido al exceso de calor (esto es, inviernos menos fríos y veranos más cálidos) que reduce el período de fructificación ${ }^{29}$.

Entrelazar en un solo análisis cambio climático y seguridad alimentaria implica también dar cuenta de los efectos provocados por las propias prácticas agrícolas. En tal sentido, destacan como factores importantes la contaminación agrícola de los recursos hídricos y el suelo, así como la emisión de gases de efecto invernadero (GEI). Al respecto, con preocupación puede constatarse que en América Latina se está siguiendo un modelo de crecimiento que no está exento de fórmulas contaminantes que dañan el suelo productivo y el medio ambiente. En algunas naciones, sin mediar el efecto nocivo, se están usando masivamente plaguicidas cuyo impacto sanitario y ambiental es insospechado. En torno a esta problemática, tanto la Organización de las Naciones Unidas para la Alimentación y la Agricultura (FAO), en su Estrategia sobre los Recursos Hídricos y el Desarrollo Agrícola Sostenible, y la Conferencia de las Naciones Unidas sobre Medio Ambiente y el Desarrollo (CNUMAD), han planteado que la agricultura sostenible constituye uno de los mayores desafíos del siglo XXI. Esta sostenibilidad supone que la agricultura no solo sea capaz de garantizar un suministro constante de

\footnotetext{
NEUESCHWANDER y ZABALETA. Loc. Cit.

9 ORTIZ. LOC. Cit.
} 
alimentos, sino que sus efectos ambientales, socioeconómicos y sanitarios sean reconocidos y contemplados en los planes nacionales de desarrollo.

Cabe hacer notar que las repercusiones del cambio climático proyectadas podrían ser modificadas por la adopción de medidas de gestión del riesgo y de estrategias de adaptación que fortalezcan la capacidad de intervención y la resistencia. Ahora bien, como el cambio climático no afectará a todos los sistemas de la misma forma, es de suma necesidad evaluar los diferentes enfoques de políticas y programas. Al mismo tiempo, las opciones en materia de políticas que influyen en la evolución de los sistemas agrícolas, que pueden afectar al cambio climático y la seguridad alimentaria.

Si se tiene en consideración que el 2010 el Gobierno de Sebastián Piñera planteó como uno de los desafíos, en materia de competitividad y desarrollo, conducir al país hacia su consolidación como "Potencia Alimentaria" a nivel mundial, la temática expuesta cobra aun mayor relevancia. Así mismo, posiciona un conjunto de interrogantes en torno al diseño de la estrategia nacional dispuesta para el cumplimiento de dicho objetivo, así como en torno a las medidas proyectadas para "remover los obstáculos o restricciones que impidan la sustentabilidad de dicha estrategia", cuya promoción fue encargada a la Comisión asesora del Ministro de Agricultura para la Industria Alimentaria chilena -creada cuatro años antes durante el gobierno de la presidenta Michelle Bachelet. En este marco, la observación del desempeño de dicha comisión resulta fundamental, pues se le asignó la misión de asesorar al ministro del ramo en todo cuanto dijera relación con la identificación, formulación y ejecución de una estrategia nacional y de las políticas, planes, programas, medidas y demás actividades relativas a la consolidación de Chile como potencia alimentaria, y a servir de instancia de coordinación entre los organismos con competencias asociadas a dichas materias.

En ese ámbito, desde la mirada de la seguridad y la defensa, cualquier medida que se tome en el sentido de mitigar los efectos que el cambio climático tenga sobre los cultivos agrícolas que puedan afectar al país, debe apuntar a la disminución del nivel de riesgo alimentario para la población, en el sentido de asegurar la producción y abastecimiento, así como la mantención de la capacidad exportadora, de manera de avanzar en su calidad de potencia alimentaria.

\section{CHILE FRENTE A LOS DESAFÍOS DEL CAMBIO CLIMÁTICO Y SUS POTENCIALES RIESGOS PARA LA SEGURIDAD ALIMENTARIA}

Conocer el marco regulatorio y las prácticas que desde el Estado se realizan actualmente, y las que se proyectan, para la adaptación de la agricultura chilena al cambio climático y mitigar sus efectos, implica al menos una aproximación a la normativa vigente en torno a esta temática, así como una mirada al quehacer de aquellos organismos institucionales sobre los que recae la responsabilidad de 
trazar los lineamientos generales para el desarrollo de la actividad agropecuaria en el país. Una de las fuentes previstas para ello fue el Perfil de País publicado por el Portal Regional para la Transferencia de Tecnología y la Acción frente al Cambio Climático en América Latina y el Caribe. También se consideró particularmente relevante sondear el desempeño de la Comisión Asesora del Ministro de Agricultura para la Industria Alimentaria Chilena.

Con fecha 8 de octubre de 2006, se promulgó el Decreto № 95 mediante el cual se formó la "Comisión Asesora del Ministro de Agricultura para la Industria Alimentaria Chilena". Según su artículo $3^{\circ}$, ésta sería presidida por el Ministro de Agricultura y la integrarían además una treintena de organismos, tanto fiscales como privados, estos son los siguientes:

1. La Subsecretaría de Agricultura.

2. El Subsecretario General de la Presidencia.

3. La Subsecretaria de Salud Pública.

4. El Director General de Relaciones Económicas Internacionales del Ministerio de Relaciones Exteriores.

5. El Director Nacional de la Oficina de Estudios y Políticas Agrarias (ODEPA).

6. El Director del Servicio Agrícola y Ganadero (SAG).

7. El Director Nacional del Instituto de Desarrollo Agropecuario (INDAP).

8. El Vicepresidente Ejecutivo de la Corporación de Fomento de la Producción (CORFO).

9. El Director del Servicio Nacional de Capacitación y Empleo (SENCE).

10. El Director Nacional del Servicio Nacional de Aduanas.

11. La Directora de la Dirección de Promoción de Exportaciones (Prochile).

12. El Vicepresidente Ejecutivo del Consejo de Rectores de las Universidades Chilenas.

13. El Presidente del Consejo de Innovación para la Competitividad.

14. El Presidente de la Fundación Chile.

15. El Presidente de la Federación de Productores de Frutas de Chile (FEDEFRUTA).

16. El Presidente de la Asociación de Productores Avícolas de Chile (APA) y de la Asociación de Productores de Cerdos de Chile (ASPROCER).

17. El Presidente de la Asociación de Exportadores de Chile (ASOEX).

18. El Presidente de la Asociación de Plantas Faenadoras Frigoríficas de Carnes (FAENACAR).

19. El Presidente de la Asociación de Empresas de Alimentos de Chile (Chilealimentos).

20. El Presidente de la Asociación de Exportadores de Productos Lácteos (EXPORLAC).

21. El Presidente de la Asociación de Productores de Aceite de Oliva (CHILEOLIVA). 
22. El Presidente de la Asociación de la Industria del Salmón de Chile (SALMONCHILE).

23. Un representante de la Asociación de Productores de Vinos Finos de Exportación (CHILEVID) y de la Asociación de Viñas de Chile, nombrado de común acuerdo por ellas.

24. El Presidente de la Sociedad Nacional de Pesca (SONAPESCA).

25. El Presidente de la Sociedad Nacional de Agricultura (SNA).

26. El Presidente del Consorcio Agrícola del Sur (CAS).

27. El Presidente del Movimiento Unitario Campesino y Etnias de Chile (MU$\mathrm{CECH}$ ).

28. El Presidente de la Confederación Nacional La Voz del Campo.

29. El Presidente de la Fundación Cinco al Día.

30. Director Ejecutivo de la Agencia Chilena para la Calidad e Inocuidad Alimentaria, Achipia.

Sin perjuicio de lo anterior, la Comisión puede invitar a participar a otros funcionarios de la Administración del Estado, así como a personalidades de reconocida competencia de los ámbitos político, social, científico o académico, funcionarios públicos de alto nivel, expertos o personas, nacionales o extranjeras, de diversos sectores.

El 3 de abril de 2013 es ampliado el presente Decreto, mediante lo cual se le autoriza al Presidente de la Comisión a nombrar un Secretario Ejecutivo, sirviendo específicamente como un elemento coordinador entre el Presidente y los delegados de los organismos de la Administración del Estado.

Como ya se adelantó, lo esencial del quehacer de la Comisión es asesorar al ministro en todo lo relacionado con la identificación, formulación y ejecución de una estrategia nacional y de las políticas, planes, programas, medidas y demás actividades relativas a la consolidación de Chile como potencia alimentaria, debiendo sesionar al menos cuatro veces por año.

Mediante documento $N^{\circ} 18.219$, la comisión le solicitó al Ministerio de Agricultura las actas de las reuniones del Presidente del Comité con los representantes de los 30 organismos, con el propósito de analizar y conocer las propuestas que se hicieron a la autoridad. En esa instancia se remitieron antecedentes de octubre de 2006 y que dicen relación con reuniones del Consejo "Chile como Potencia Alimentaria" y que proponen interesantes iniciativas que deben ser tomadas como orientaciones para el Ministro de Agricultura, con el propósito que estas directrices puedan ser consideradas a futuro como políticas públicas.

El objetivo esencial de este estudio es lograr que Chile se constituya en una potencia alimentaria, buscando mecanismos que permitan el desarrollo de todo el sector agropecuario, potenciándose como una poderosa industria de alimentos, dada las consideraciones que tienen como respuesta las amenazas que enfrenta este rubro buscando, además, cohesionar mediante una estrategia al 
sector público (estatal) y al privado, única forma de lograr posicionarla a nivel internacional. Los plazos que se fijaron para esta condición, señalan que dentro de diez años Chile debía ubicarse dentro de los diez principales exportadores de alimentos del mundo, generando con ello unos 50.000 nuevos empleos.

Para alcanzar lo anterior, se propuso estructurar líneas de acción que las conoceremos seguidamente:

1. Estimular estrategias que busquen desarrollar alianzas y métodos productivos, entre los sectores primarios, la industria procesadora y la distribución. En este sentido se pretende potenciar el desarrollo del sector, pero de manera integral, es decir, que permita alcanzar un mejoramiento en el bienestar de los pequeños y medianos productores, pero deben provenir de esfuerzos conjuntos entre lo estatal y lo privado principalmente.

Otro aspecto esencial es que debe desarrollarse como una agricultura limpia y de calidad, logrando que los pequeños y medianos productores alcancen niveles de excelencia internacional. En efecto, se trata de exportar productos con un alto valor (sanitario, inocuidad, origen, orgánico, organoléptico, ambientales, etc.). Para esto el capital humano es fundamental, inicialmente y de manera prioritaria cortoplacista, es entregarle la capacitación y en una mirada más a largo plazo, es coordinarse con institutos de formación técnico y profesional que sean capaces de instruir y preparar especialmente a los jóvenes que se integren a las labores del sector. Finalmente, sobre esto podemos señalar que la infraestructura es esencial para este objetivo. Si bien el país cuenta con amplias carreteras, modernos puertos y aeropuertos, mientras que en el ámbito de la producción primaria y mediana están dotados de servicios eléctricos, agua potable y alcantarillados, de igual manera preocupa la condición de lo rural en el plano del pequeño productor que aún carece de los citados servicios.

2. Generar estrategias de inserción competitiva en los mercados internacionales. Para esto es de importancia aprovechar los diversos tratados de libre comercio que ha firmado Chile y asignándoles responsabilidades concretas a los agregados agrícolas que cumplen esa importante función en algunos países, proporcionando información, y con eso priorizar las demandas del mercado, buscar el intercambio de tecnologías, capacitación y especialización para los trabajadores del sector, etc.

Para lograr lo anterior, es indispensable que se desarrolle una estrategia que diga relación con la Imagen País, siendo una herramienta cardinal para mantener los niveles de competitividad con otros países productores de alimentos; en este mismo orden, también es prioritario el fortalecimiento de políticas que dicen relación con la protección y mejoramiento de las medidas fito y zoosanitarios, dado que en la medida que el país sea capaz 
de mantener y mejorar esta condición, le reportará un mejor posicionamiento en el concierto internacional.

Un aspecto que no debe ser dejado de lado es mejorar y fortalecer los mercados internos, especialmente mirado desde una postura más bien ética, es decir, los conciudadanos tienen los mismos derechos de acceder a productos con estándares internacionales, tanto en tamaño, calidad y seguridad y no solo consumir aquello que no cumple los parámetros de importación.

3. La tercera línea de acción dice relación con el tema tecnológico y de investigación tanto del mundo privado como del público. Este elemento juega un rol muy importante en la innovación y el desarrollo, para lograr dichos propósitos se debe motivar especialmente al sector privado, teniendo en cuenta que los principales países productores de alimentos son aquellos que invierten importantes sumas de dinero proveniente del mundo proyectos de investigación, entre otras iniciativas. Tanto es así, que los países desarrollados han construido escuelas, academias, institutos y universidades para el estudio y la investigación en beneficio de este sector productor.

4. Otro punto importante propuesto por el Comité para alcanzar los objetivos es la modernización del sector, tanto en su infraestructura como en las políticas que lo rigen, para ello se ha estimado adecuar algunos roles en cuanto a la regulación, control y certificación de las exportaciones, ya que muchas de ellas datan de la década de los años 60 y han perdido vigencia con la modernidad del sector a nivel internacional. Tampoco queda exento de preocupación el tema de la regulación laboral, debiendo resolver aspectos de precariedad gremial, necesarias para el buen desempeño en un marco de bienestar y de responsabilidad social.

5. Un punto necesario de considerar es aquel que dice relación con la salud de los consumidores, buscando que los productos no tan solo sean seguros en el consumo, sino que sean saludables y eviten la producción de enfermedades, tales como diabetes, cáncer, obesidad, problemas cardiovasculares, entre otras; de modo que con este antecedente los productores deben buscar la diversificación, entregando a los mercados frutas y verduras que aporten fibra y antioxidantes, especialmente para el consumo de la población mayor. Para esta condición, la Comisión propone dos iniciativas esenciales: a) Destacar el valor nutricional de los productos que Chile exporta, b) Mejorar el consumo interno con productos sanos y seguros. Finalmente, se sugiere elaborar una agenda comunicacional que abarque los principales aspectos de lo que se está haciendo en el sector alimentario, recomendando que su difusión sea interna y externa. 
Como propuesta de trabajo, se definió que la Comisión trabajase conforme se organizaron inicialmente, es decir, cuatro reuniones de trabajo al año como mínimo, y al mismo tiempo, les entregó facultades a los coordinadores para que elaborasen su propia agenda, asignándoles tareas y responsabilidades a los organismos que se enuncian:

- Grupo de Trabajo № 1: Impulsar Estrategias de Fomento.

- Grupo de Trabajo No 2: Profundizar las Estrategias de inserción competitiva en los mercados.

- Grupo de Trabajo Nº 3: Desarrollar la Innovación y Desarrollo Tecnológico Agroalimentario.

- Grupo de Trabajo No 4: Modernizar la Institucionalidad Sectorial.

- Grupo de Trabajo N ${ }^{\circ}$ 5: Difundir la Estrategia de Chile, como Potencia Alimentaria.

Según se aprecia, en ninguna de estas definiciones generales la Comisión hace referencia al cambio climático y la seguridad alimentaria, asunto para nada ajenos a la definición de directrices para impulsar una estrategia de desarrollo para el sector.

Con la expectativa de sondear referencias explícitas sobre estos asuntos, mediante una solicitud emitida a través de la Ley de Transparencia al Ministerio respectivo, fueron requeridas las actas de sesión de la comisión y sus respectivas comisiones. Lamentablemente, se nos informó de la inexistencia de registros que den cuenta del quehacer de la Comisión. Dado este hecho, de aquí en más el análisis se focaliza en los antecedentes aportados por el Perfil de País elaborado por PNUMA, publicado por el Portal Regional para la Transferencia de Tecnología y la Acción frente al Cambio Climático en América Latina y el Caribe, referido puntualmente a la descripción del marco regulatorio y financiamiento dispuesto por Chile para enfrentar el cambio climático.

Según lo señala este reporte, en términos de instrumentos de política y estrategia, el 2006 Chile adoptó una Estrategia Nacional de Cambio Climático, articulada sobre tres ejes temáticos: (i) la adaptación a los impactos del cambio climático; (ii) la mitigación de las emisiones de gases de efecto invernadero; y (iii) la creación y fomento de capacidades en cambio climático. Allí se establece que en materia de adaptación los objetivos para el país son: la evaluación de los impactos ambientales y socioeconómicos del cambio climático en Chile, la definición de medidas de adaptación; y la ejecución y seguimiento de las medidas de adaptación. Este punto se entrelaza directamente con lo definido para la primera línea de acción de la Comisión Asesora del Ministro de Agricultura para la Industria Alimentaria Chilena.

Dos año más tarde, el Gobierno elaboró un Plan de Acción para el Cambio Climático 2008-2012, el cual aún no ha sido actualizado, cuyo objetivo prioritario fue definir escenarios futuros de vulnerabilidad al cambio climático en sectores 
prioritarios con el propósito de evaluar los impactos ambientales, socio-económicos y sanitarios de este fenómeno, permitiendo con esta información definir medidas nacionales y sectoriales de adaptación al cambio climático. Este plan de acción determina, en particular, que los sectores silvo-agropecuario, energía, infraestructura, salud y pesca, deben desarrollar un plan sectorial de adaptación. Más allá de lo propuesto, a la fecha solo han sido desarrollados y publicados los planes de adaptación al cambio climático para el sector silvoagropecuario y para la biodiversidad. Estando aún en desarrollo los planes de adaptación al cambio climático para el sector pesca y acuicultura, para salud, para la infraestructura, para ciudades, para el sector turismo, para el sector energía y para los recursos hídricos.

Con respecto a la aplicación y cumplimiento del Plan de Acción para el Cambio Climático 2008-2012, desde el propio gobierno se ha realizado una evaluación de medio término y, en el presente, se están discutiendo mecanismos para incorporar indicadores que permitan realizar un monitoreo del cumplimiento, tanto para el Plan Nacional, como para los planes sectoriales bajo desarrollo. El Ministerio de Ambiente también coordina el proyecto MAPS-Chile, por el cual se busca analizar las proyecciones y modelos de emisiones para Chile y fomentar medidas de mitigación al cambio climático. Bajo este escenario de apertura al debate, parece posible incluir el tema de la seguridad alimentaria como una arista del los desafíos que plantea el cambio climático.

En materia de suscripción a acuerdos internacionales y acciones relacionadas, junto con ratificar el Convenio Marco de Naciones Unidas sobre el Cambio Climático (CMNUCC, 1994) y su Protocolo de Kioto (2002), el Convenio sobre la Diversidad Biológica (CDB, 1994) y el Convenio de Naciones Unidas para el Combate a la Desertificación (UNCCD, 1997), el 2010 presentó Medidas Nacionales de Mitigación Apropiadas para cada País (NAMA). De esta manera se asumió el desafío de lograr una desviación del $20 \%$ sobre las proyecciones de emisiones al 2020 realizadas en el año 2007. Para cumplir este objetivo, Chile solicitó apoyo financiero y puso el foco de las acciones en los sectores de eficiencia energética, energía renovable y uso de la tierra, cambio de uso de la tierra y forestación.

En cuanto a financiamiento para enfrentar el cambio climático, como un aspecto relevante cabe señalar que Chile no tiene proyectos aprobados en el Fondo de Adaptación. El resto de los fondos a los cuales ha accedido, se enfocan principalmente a financiar iniciativas de innovación energética. Preocupa en tal sentido la ausencia de proyectos conducentes, por ejemplo, a canalizar recursos que permitan asistir a pequeños productores agropecuarios para adaptarse al cambio climático (como ocurre en Uruguay), o a generar proyectos sobre adaptación y manejo agrícola sustentable (en el caso Argentino), por mencionar algunos. 


\section{ALGUNAS RECOMENDACIONES PARA EL DISEÑO DE UNA POLÍTICA PÚBLICA EN LA MATERIA}

Como la intención de este estudio es proponer algunos puntos relevantes a tener en consideración para afrontar los desafíos presentes y futuros en materia de seguridad alimentaria, sobre la base de los antecedentes expuestos en páginas anteriores, a continuación se puntualizan algunas ideas a tener en consideración para actualizar el debate en torno a la seguridad alimentaria en el país:

1. Salud

El no desarrollo de políticas públicas asociadas a las fuentes de alimentación de nuestro país, encarecerán el gasto y salud de una población que vive más años y que exige del Estado fondos para tratar enfermedades asociadas a una dieta incorrecta con alto contenido de grasas saturadas y carbohidratos.

\section{Financiera}

Hay un riesgo de flujo de caja, pues se necesita invertir fuertes sumas en semillas, mano de obra, plantas para procesar harinas, y el resultado muchas veces depende de un mercado de alimentos con precios fluctuantes que pueden hacer que el precio de venta del alimento no cubra la inversión produciéndose un problema financiero.

Además, como se recibe el dinero al término de las cosechas o de los procesos productivos, de no contar con apoyo estatal ese plazo puede general la quiebra de una empresa alimentaria.

La conversión de un terreno destinado a determinado alimento versus otro requiere de un plazo no menor que puede implicar falta de liquidez para continuar con la operación.

\section{Económica}

Dada la alta empleabilidad de mano de obra que genera la industria alimentaria, su reducción puede desencadenar significativas tasas de cesantía en los campos de nuestro país al no poder convertir a esos trabajadores a otra actividad económica.

\section{Estructural}

La estructura productiva puede pasar de un país como el nuestro fuerte en servicios, a un país con plantas productivas especializadas en alimentos. 


\section{Investigación $D+1$}

El uso de tecnología es clave para obtener buenos rendimientos en paños que de otra manera serán más rentables si se destinan, por ejemplo, en inversiones inmobiliarias. En la medida que exista asociatividad con centros de investigación y con universidades en Chile y el extranjero, de manera perentoria vamos a tener que hacer desarrollo en investigación, apuntando a la creación de especialidades en universidades en la industria alimentaria.

\section{Laboral}

El desarrollo de estructura productiva dentro de una cadena alimentaria va a generar puestos de trabajo en las distintas regiones de nuestro país, serán polos de desarrollo de mano de obra, estos puestos son mayores si los comparamos con los puestos de trabajo que se logran si es que importáramos dichos alimentos.

\section{Educacional}

Hoy en día consumir una dieta saludable es en la mayoría de los casos más cara que una dieta de comida rápida a un tercio de su valor, en la medida que tengamos un desarrollo alimentario lograremos educar de mejor manera a los niños de nuestro país evitando riesgos de obesidad, tasas de diabetes infantil, etc.

\section{Asociatividad comercial}

El no desarrollar una política pública de inocuidad y de desarrollo alimentario nos aleja de poder lograr asociatividad comercial en la cadena de valor de la industria alimentaria, al no poder por ejemplo contar con tecnología alemana para el desarrollo de cadenas de frío de ciertos insumos o productos terminados, el no poder asociarnos con empresas francesas expertas en el trabajo de harinas y sales para los alimentos, el no contar con la tecnología de empresas estadounidenses expertas en empaque de alimentos, etc.

\section{Estratégico}

El que el país dependa de ciertas importaciones para alimentos nos pone en una clara amenaza de tener desabasteciendo y ello puede acarrear descontento social, saqueos y muchos problemas difíciles de manejar.

\section{0. Índice de riesgo país}

Un país con una sólida y consolidada industria alimentaria ante los ojos de la comunidad internacional presenta menos riesgos de que su población 
se vea afectada para trabajar y desarrollar sus actividades normales, pudiendo por tanto aportar el PGB del país de manera sólida y permanente, con lo cual ante los ojos de organismos internacionales estamos con un bajo riesgo social y de estructura alimentaria.

\section{A MODO DE CONCLUSIÓN...}

La evidencia expuesta apoya la necesidad de delimitar una estrategia nacional que permita definir medidas de adaptación y mitigación hacia un enfoque climático inteligente de "sistemas alimentarios", aspecto fundamental para proyectar una agricultura más resistente a las influencias del cambio climático sobre la seguridad alimentaria.

En este sentido, es esencial generar políticas públicas eficientes y realistas que permitan disminuir las eventuales amenazas que constituyen un peligro para el desarrollo alimentario de la población:

1. Tener plena conciencia sobre el cambio climático y en qué medida este afecta al mundo en general, y a Chile en lo particular, dado que es evidente el aumento de las temperaturas extremas, la escasez de agua y las inundaciones provocadas por océanos en diversos países y que ha significado, por una parte, la pérdida definitiva de espacios que eran aptos para la práctica agrícola y, por otra, la reducción en tamaño de algunos animales y plantas debilitando las fuentes alimentarias esenciales para la nutrición de la población.

2. La práctica agrícola debe modernizarse y actualizarse a fin de proveer una seguridad alimentaria al país, y debe efectuar sus cambios de acuerdo al crecimiento y nuevas condiciones naturales que le imprime el medio ambiente, de manera que debe imperiosamente adaptar un agrosistema con patrones climáticos de acuerdo a las nuevas condiciones naturales y que, además, le permitan ser capaces de enfrentar cambios bruscos y variables en el ambiente donde se producen alimentos.

En este sentido, la inseguridad agro productora, respecto de las variaciones u oscilaciones a las temperaturas, genera efectos nocivos de enormes consecuencias, lo que produce una lógica desmotivación de los productores, ejemplo de esto es el arroz, cada grado de temperatura que aumente reduce en un 10 por ciento la producción de este producto; en consecuencia, se debe insistir que la agricultura debe adaptarse al cambio de manera que todos estos agentes naturales podrían seguir afectándola en el tiempo.

3. Otra amenaza que afecta a la producción alimentaria son los recursos hídricos y el suelo, cuyos efectos son provocados por las propias prácticas agrícolas, especialmente por el uso de plaguicidas, ocasionando efectos nocivos y contaminantes, estimándose que la única manera de minimizar 
sus efectos e idealmente erradicarlos es considerar estas prácticas en los respectivos planes nacionales y, de esta manera, se presume que en el tiempo se podrían evitar algunos efectos negativos tanto en lo ambiental, sanitario, socioeconómico, cultural, etc.

4. Elaborar políticas públicas efectivas y que se relacionen con el quehacer de otras similares de los demás ministerios, como por ejemplo con salud ya que se asocia con esta área, entre otras por el tema de la nutrición de una dieta apta y sana evitando los carbohidratos y grasas saturadas que son los agentes provocadores de las actuales enfermedades considerando, además, que la población se ha tornado más longeva, en consecuencia se les debe proveer de una alimentación segura, sana y eficiente.

5. En relación con la carteras del Trabajo, Economía y Obras Públicas, se puede avanzar, en cuanto a la primera, en el otorgamiento de recursos como apoyo del Estado debido esencialmente a las fluctuaciones de precios y, en ese sentido, le otorga una seguridad concreta al productor agrícola. En relación con la mano de obra y la cartera respectiva, la industria alimentaria es de alta empleabilidad, de modo que debe ser atractiva y de esa manera evitar los altos índices de desempleo y preocuparse de la estabilidad social de contratados y ser eficientes en la reconversión social cuando se produzca la motivación de trabajar en los campos y en la industria alimentaria.

6. La visión multidimensional que el Estado debe adoptar, tiene que orientarse a visualizar las posibles soluciones como un todo armónico con visión de país, que fortalezcan los proceso productivos, de distribución, almacenamiento, transporte y estrategias de posicionamiento en el mercado internacional; ello permitirá colocar al Estado como una potencia alimentaria, e incentivará a los grandes, medianos y pequeños productores para mantener los flujos productivos evitando los riesgos de una baja productividad, y tomando medidas que permitan paliar el efecto del cambio climático, tema que hoy por hoy ocupa la agenda internacional. Lo anterior permitiría disminuir los índices de vulnerabilidad del país y los efectos que ello podría ocasionar directa o indirectamente en el ámbito de la seguridad del Estado.

7. Finalmente, la educación y la capacitación son esenciales; por una parte la preparación de los trabajadores en todos los niveles de la cadena alimentaria, estos deben ser entrenados y preparados a fin de lograr innovar en el quehacer de la industria alimentaria y, por otra, se debe educar a la población informándoles sobre la nutrición, señalándoles claramente los peligros actuales y las nuevas patologías producidas a raíz de la alimentación y, con ello, evitar el consumo de dietas que produzcan daños a la salud, especialmente en la población infantil y juvenil, indicándoles los riesgos que produce la obesidad, la diabetes infantil y las enfermedades de índole cardíacas, entre otras. 


\section{REFERENCIAS BIBLIOGRÁFICAS}

ALDUNCE, Paulina y NERI, Carolina y SZLAFSZTEIN, Claudio. Hacia la evaluación de prácticas de adaptación ante la variabilidad y el cambio climático. s.I., NUMA / UFPA, 2008.

BANFI Piazza, Silvio. Evolución del mercado de las lentejas. Santiago, ODEPA, 2014.

BANFI Piazza, Silvio. Cultivo de porotos en perspectiva. Santiago, ODEPA, 2014.

BARROS, Vicente. El Cambio Climático Global. ¿Cuántas catástrofes antes de actuar? Buenos Aires, Libros del Zorzal, 2005. 176p.

BATES, B. y otros. El cambio climático y el agua. Ginebra, PNUMA y Organización Meteorológica Mundial, 2008, 212p.

BUZZETTI, Carolina y GARCÍA, Andrea. Trigo: situación y perspectivas. Santiago, ODEPA, 2015.

CHONCHOL, Jacques. Desafío alimentario: el hambre en el mundo. Santiago, LOM, 1991. 195p.

CLARO, Edmundo. Integrando la adaptación al cambio climático en las políticas de desarrollo: ¿Cómo estamos en Chile? REDESMA [online], 63(2): 63-72, 2008.

CONDE, Cecilia y SALDAÑA, Sergio. Cambio climático en América Latina y el Caribe: impactos, vulnerabilidad y adaptación. Ambiente y Desarrollo, Santiago, 23(2): 23-30, 2007.

Departamento de Política Agraria. Evolución del consumo aparente de los principales alimentos en Chile: 2003-2013. Santiago, ODEPA, 2014.

GARREAUD, René. Cambio climático: Bases físicas e impactos en Chile. Tierra Adentro, Santiago, (93): 13-19, marzo-abril, 2011.

HLPE. La seguridad alimentaria y el cambio climático. Un informe del Grupo de alto nivel de expertos en seguridad alimentaria y nutrición del Comité de Seguridad Alimentaria Mundial, Roma, HLPE, 2012. 115p.

LAURE, Martín. Los efectos diferenciados de la liberalización comercial en Chile sobre zonas rurales en la VI Región de O'Higgins y la IX Región de la Araucanía. Santiago, FAO, 2013. 67p.

LOBELL, David, SCHLENKER, Wolfram y COSTA-ROBERTS, Justin. Climate trends and global crop production since 1980. Science, s.I., 333(6042): 616-620, july, 2011. 
MIA, Irene. Midiendo el estado de la seguridad alimentaria en Chile en una perspectiva internacional. Los hallazgos del Índice de Seguridad Alimentaria. Santiago, The Economist, Economist Intelligence Unit, 2013. 28p.

MUÑOZ Villagrán, Marcelo. Maíz: alza en precios nacionales. Santiago, ODEPA, 2014.

MUÑOZ Villagrán, Marcelo. Arroz: baja la producción mundial. Santiago, ODEPA, 2014.

MUÑOZ Villagrán, Marcelo. Maíz: se aproxima una temporada complicada. Santiago, ODEPA, 2013.

MUÑOZ, Francisco. La política del cambio climático. Madrid, Alianza, 2010. 303p.

NEUESCHWANDER, Aquiles y ZABALETA, Juan. El Cambio Climático en el Sector Silvoagropecuario de Chile. Fundación para la Innovación Agraria, Santiago, 29 noviembre, 2010.

Oficina de Estudios y Políticas Agrarias. Consumo aparente de principales alimentos en Chile. Santiago, ODEPA, 2012.

Oficina de Cambio Climático. Plan Nacional de Adaptación al Cambio Climático. Santiago, Ministerio del Medio Ambiente, 2014, 55 p.

ORDOÑES, José Antonio y MASERA, Omar. Captura de carbono ante el cambio climático. Madera y Bosques, s.I., 7(1): 3-12, 2001.

Organización de las Naciones Unidas para la Alimentación y la Agricultura. Cambio climático y seguridad alimentaria: un documento marco. Roma, FAO, 2007. 24p.

Organización de las Naciones Unidas para la Alimentación y la Agricultura. Panorama de la seguridad alimentaria y nutricional en América Latina y el Caribe. Roma, FAO, 2013.

ORTIZ, Rodomiro. El cambio climático y la producción agrícola. s.I., BID, 2012. $41 \mathrm{p}$.

SANTIBAÑEZ, Fernando. El cambio climático y los recursos hídricos en Chile. Santiago, ODEPA, 2016. 60p.

SCHMIDHUBER, Josef y TUBIELLO, Francesco. Global food security under climate change, Proceedings of the National Academy of Sciences, Boston, 104(50): 19703-19708, december, 2007.

SHERIDAN, Jennifer y BICKFORD, David. Shrinking body size as an ecological response to climate change. Nature Climate Change, s.l., 1(8): 401-406, october, 2011. 
STERN, Nicholas. El informe Stern: la verdad sobre el cambio climático. Barcelona, 2007, 389p.

TAPIA Cruz, Bernabé. Mercado de la papa. Santiago, ODEPA, 2014.

WILKES, Andreas, TENNIGKEIT, Timm y SOLYMOSI, Katalin, Planificación nacional para la mitigación de GEI en la agricultura: Documento de orientación. FAO, Serie de Mitigación de Cambio Climático en la Agricultura, 8, 2013

WHEELER, Tim y VON BRAUN, Joachim. Climate change impacts on global food security. Science, s.l., 2013, 341(6145): 508-513, august, 2013. 


\section{ANEXO 1 \\ Categorías e indicadores del Global Food Security Index (GFSI) \\ 1. Asequibilidad}

A. El consumo de alimentos como proporción del gasto de los hogares: Una medida del porcentaje de gasto de los hogares que se gasta en alimentos a nivel nacional.

B. Proporción de la población bajo la línea de la pobreza mundial: Porcentaje de población que vive por debajo de $\$ 2$ / día PPP.

C. El producto interno bruto per cápita (PPP): US \$ en PPA / cápita.

D. Los aranceles de importación agrícolas: Medido como el promedio de los aranceles de nación más favorecida (NMF) a todas las importaciones agrícolas.

E. Presencia de los programas de redes de seguridad alimentaria: Una medida de las iniciativas públicas para proteger a los pobres de las crisis relacionadas con los alimentos. Este indicador tiene en cuenta los programas de seguridad alimentaria netas, que incluyen las transferencias en especie de alimentos; las transferencias condicionadas de efectivo (es decir, vales para comida); y la existencia de programas de alimentación escolar por parte del Gobierno, ONG, sector o multilateral.

F. El acceso a la financiación para los agricultores: Este indicador se califica en una escala de 0-4 en base a la profundidad y el alcance de la financiación de los agricultores. La metodología de puntuación se actualiza para el índice de 2013.

\section{Disponibilidad}

A. La suficiencia del suministro: Un indicador compuesto que mide la disponibilidad de alimentos a través del suministro de alimentos en kcal / cápita / día y los niveles de ayuda alimentaria.

- Suministro de comida normal: Una estimación de la cantidad per cápita de alimentos disponibles para el consumo humano.

- La dependencia de la ayuda alimentaria crónica: Mide si un país es un receptor de ayuda alimentaria crónica. A los efectos de este índice, los receptores de ayudas crónicas se definen como aquellos países que han recibido ayuda alimentaria de emergencia durante un lapso de tiempo de cinco años.

B. El gasto público en I + D agrícola: Una medida del gasto público en investigación y desarrollo agrícola. El gasto en I + $D$ agrícola es un proxy para la innovación y la tecnología agrícola que aumenta la eficiencia del mercado y el acceso.

C. Infraestructura agrícola: Indicador compuesto que mide la capacidad de almacenar y transportar productos al mercado. 
- Existencia de instalaciones de almacenamiento de cultivos adecuada: Evaluación cualitativa de la presencia de suficientes instalaciones de almacenamiento de las cosechas en función del tamaño del sector agrícola y de la población.

- La infraestructura vial: Indicador cualitativo para medir la calidad de la infraestructura vial.

- La infraestructura portuaria: Indicador cualitativo para medir la calidad de la infraestructura portuaria.

D. La volatilidad de la producción agrícola: La desviación estándar del crecimiento de la producción agrícola durante el último período de veinte años para los cuales hay datos disponibles.

E. Riesgo la estabilidad política: Una medida de la inestabilidad política en general. La inestabilidad política tiene el potencial de interrumpir el acceso a los alimentos a través de vías tales como bloques de transporte o compromisos de ayuda alimentaria reducidos.

F. Corrupción: Este indicador mide la capacidad de penetración de la corrupción en un país mediante la evaluación del riesgo de corrupción. La corrupción puede afectar la disponibilidad de alimentos a través de las distorsiones e ineficiencias en el uso de los recursos naturales, así como las ineficiencias de cuello de botella en la distribución de alimentos.

G. Capacidad de absorción urbana: Una medida de la capacidad de un país para absorber las tensiones impuestas por la urbanización y garantizar aun la seguridad alimentaria.

H. Pérdida de alimentos: Una medida de post-cosecha y la pérdida de alimentos antes del consumo como una proporción de la oferta total interna (producción, importaciones netas y variación de existencias) de cultivos, ganado y peces materias primas, en toneladas.

\section{Calidad y seguridad}

A. Diversificación de la dieta: La parte de los alimentos que no contengan almidón (todos excepto cereales, raíces y tubérculos) en el consumo total de energía alimentaria.

B. Los niveles de nutrición: indicador compuesto que mide el compromiso del gobierno de aumentar los niveles de nutrición.

- Las directrices nacionales dietéticas: indicador binario para medir si el gobierno ha publicado directrices para una dieta equilibrada y nutritiva.

- Plan nacional de nutrición o estrategia: indicador binario para medir si el gobierno ha publicado una estrategia nacional para mejorar la nutrición.

- El seguimiento y la vigilancia de la nutrición: indicador binario medir si el gobierno controla el estado nutricional de la población en general. Ejem- 
plos de seguimiento y vigilancia incluyen la recopilación de datos sobre la desnutrición, las deficiencias relacionadas con la nutrición, etc.

C. La disponibilidad de micronutrientes: indicador compuesto que mide la disponibilidad de hierro y vitamina $A$ en el suministro de alimentos. Los subindicadores incluyen: disponibilidad dietética de Vitamina A, disponibilidad dietética de hierro animal, disponibilidad dietética de hierro vegetal.

D. Calidad de las proteínas: Este indicador mide los gramos de proteína de calidad consumida usando la metodología de la puntuación de aminoácidos corregidos por digestibilidad de proteinas (PDCAAS). Esta metodología evalúa la presencia de nueve aminoácidos esenciales en la dieta nacional promedio. Las entradas de este cálculo incluyen: el perfil de aminoácidos, el valor de digestibilidad de proteínas y el promedio de gramos consumidos de cada alimento que contribuye con un mínimo de $2 \%$ al consumo de proteínas.

E. Seguridad alimentaria: indicador compuesto que mide el entorno propicio para la inocuidad de los alimentos.

- Agencia para garantizar la seguridad y la salud de los alimentos: indicador binario que mide la existencia de una agencia reguladora o administrativa para garantizar la salud y seguridad de los alimentos.

- Porcentaje de población con acceso a agua potable: El acceso al agua potable es la proporción de personas que utilizan fuentes mejoradas de agua potable: conexión domiciliaria; fuente pública; pozo de sondeo; pozo excavado protegido; manantial protegido; agua de lluvia.

- Presencia del sector de la alimentación formal: Indicador cualitativo para medir la prevalencia de un sector formal de la tienda de comestibles. 